\title{
Psychiatric impact on COVID-19 patients isolated in a tertiary care hospital in Pakistan
}

Nazish Imran, ${ }^{1}$ Irum Aamer, ${ }^{2}$ Hadia Afzal, ${ }^{2}$ Ali Hashmi, ${ }^{2}$ Bilquis Shabbir ${ }^{3}$ and Aftab Asif ${ }^{2}$

${ }^{1}$ Department of Child and Family Psychiatry; ${ }^{2}$ Academic Department of Psychiatry and Behavioural Sciences; ${ }^{3}$ Department of Medicine, King Edward Medical University/Mayo Hospital, Lahore, Pakistan (Correspondence to: Nazish Imran: nazishimrandr@gmail.com)

\begin{abstract}
Background: Adverse psychological effects have been associated with COVID-19-related disease containment measures, but little is known about the psychiatric symptoms and distress.
\end{abstract}

Aims: This study aimed to explore and understand the psychiatric symptoms and distress in suspected or confirmed COVID-19 patients isolated and quarantined in hospital.

Methods: A mixed methods study was conducted in the COVID-19 units of Mayo Hospital, Lahore, Pakistan; 114 out of 160 adult patients were assessed by telephone using validated scales (Stress Reactions and Adjustment Disorder Checklist, 9-item Patient Health Questionnaire, 7-item Generalized Anxiety Disorder Scale and Insomnia Severity Index) and a few open-ended questions about expectations and anticipated areas of need during hospitalization, including experiences with isolation.

Results: The prevalence of adjustment disorder, acute stress disorder, anxiety, depressive symptoms and insomnia was $67.5 \%, 3.5 \%, 16.7 \%, 18.4 \%$, and $29.8 \%$ respectively. One male patient tried to commit suicide during the study period. Fear, anger, low mood, anxiety and sleep disturbances were the most notable psychological consequences in qualitative the responses. Inadequate communication, poor ward facilities, concerns about the health of family members and financial problems were the most commonly identified factors leading to distress.

Conclusion: Our results show alarmingly high levels of stress-related symptoms - insomnia, depression and anxiety among COVID-19 confirmed or suspected hospitalized patients. There is a need to incorporate psychological services in the acute phase of illness for prompt recognition and management of psychiatric problems.

Keywords: COVID-19, patients, hospitalization, anxiety, depression

Citation: Imran N; Aamer I; Afza H; Hashmi A; Shabbir B; Asif A. Psychiatric impact on COVID-19 patients isolated in a tertiary care hospital in Pakistan. East Mediterr Health J. 2022;28(1):5-13. https://doi.org/10.26719/emhj.21.062

Received: 29/06/20; accepted: 15/06/21

Copyright @ World Health Organization (WHO) 2022. Open Access. Some rights reserved. This work is available under the CC BY-NC-SA 3.0 IGO license (https://creativecommons.org/licenses/by-nc-sa/3.o/igo).

\section{Introduction}

The COVID-19 pandemic is one of the biggest public health challenges the world has faced in recent memory. Owing to the highly contagious nature of COVID-19, patients with the illness and those suspected of exposure to the virus are isolated and quarantined for at least 2 weeks. Apart from physical symptoms, it is not uncommon for confirmed and suspected cases of COVID-19 to suffer from significant psychological stress. Some diagnosed patients may experience it as a death sentence, leading to immediate psychological sequelae like excessive fear of disease consequences, anxiety, depression, insomnia, loneliness, denial and distress (1). High stress levels, adjustment disorders, aggressive behaviour, acute psychosis and suicide have also been reported in previous outbreaks of infectious diseases (2-4). A recent qualitative study done in the Islamic Republic of Iran highlighted the fear of death and guilt for infecting family members to be prominent psychological sequelae in infected people (5).

Evidence suggests that the psychological impact of infectious disease can be long lasting. A high prevalence of moderate to severe levels of anxiety (13-32\%), depression $(18-26 \%)$ and post-traumatic stress disorder (4\%) was found among SARS survivors 1 month following discharge from hospital (6-7). Another study done at the time of the SARS epidemic suggests that survivors had elevated stress levels even 1 year after the illness, and GHQ-12 scores indicated that more than $64 \%$ of survivors were potential psychiatric cases (8). Rejection by society and stigmatization are also consequences of strict isolation/quarantine and mandatory contact tracing (9). Psychological distress may reduce treatment adherence among confirmed and suspected COVID-19 patients.

Pakistan reported its first case of COVID-19 on 26 February 2020. This was followed by a progressive increase in the number of cases and the government imposed a lockdown in the country on 24 March 2020, which was still partially in effect at the time of writing. As of 27 June 2020, Pakistan has reported more than 198000 confirmed cases and 4035 fatalities (10). Isolation for confirmed cases and 14 days of quarantine in a hospital or designated quarantine facility starting from the day of contact was previously mandatory, and a policy of home isolation for suspected and confirmed cases was 
implemented in the second week of May. Thus, those with confirmed or suspected COVID-19 were also prone to psychological morbidity due to the compounded stress of hospitalization.

Pakistan is a developing country and has a huge burden of mental health problems, but only 400 trained psychiatrists are working in a few state run facilities in major cities of the country for a population of 220 million (11). In terms of health expenditure, the health sector gets minimal priority in the public policies and allocation decisions of the investment funds in Pakistan. According to the World Bank, Pakistan spends $2.6 \%$ of its gross domestic product on health, which is around $7.6 \%$ of total government spending (US\$ 5 per capita); this is significantly lower than countries with similar income indices, e.g. Senegal (US\$ 39 per capita) (12). There were enormous challenges in assessing and managing the psychiatric problems during the acute phase of COVID-19 as the psychiatric facilities of the hospital, including outpatient clinics, were shut down and converted into COVID-19 screening clinics. Thus, a new venture, telepsychiatry, was introduced to allow contact-free provision of psychiatric services.

With these challenges in mind, the objectives of current study were to report common psychiatric manifestations and associated factors in COVID-19 patients admitted in a designated COVID-19 treatment facility in a tertiary care hospital in Lahore, Pakistan, in order to facilitate the development and provision of patient-centred psychiatric services. Our study aimed to highlight the urgent need for psychological interventions for hospitalized COVID-19 patients in a low- and middleincome country during the current crisis.

\section{Methods}

This was a cross-sectional study using a mixed methods approach conducted in the COVID-19 units of Mayo Hospital, Lahore Pakistan from April to May 2020. Mayo Hospital is the largest tertiary care hospital in the province of Punjab (population 11 million, 2017) and was the main referral centre for the care and management of COVID-19 patients during the early outbreak in Lahore city. Ethical approval was obtained from the institutional review board of King Edward Medical University, which is affiliated with Mayo Hospital, Lahore before the commencement of study.

The sampling technique was purposive convenience sampling. Because the hospital was employing total barrier nursing, patients were contacted for interview by telephone and video calls to provide support and detect and treat possible psychiatric symptoms. Informed consent was obtained from all participants and they were allowed to terminate the interview at any time they wished. Inclusion criteria were: hospitalized patients with confirmed or suspected COVID-19 infection, patient's willingness to cooperate in research, and patients being stable medically to participate. Patients with significant medical issues which made communication difficult and/or those with altered mental status were excluded. We assessed 114 isolated and quarantined hospitalized patients using validated scales and open-ended questions about expectations and anticipated areas of need during hospitalization as well as experiences with quarantine or isolation. This mixed methods approach allowed an in-depth assessment of the psychological impact of COVID-19 illness in hospitalized patients.

The modified version of the Stress Reactions Checklist used in a previous study gives the criteria for acute stress disorder according to the Diagnostic and Statistical Manual of Mental Disorders (DSM-5) and related emotional and behavioural changes (13). The DSM-5 criteria were used to diagnose adjustment disorder. The 9-item Patient Health Questionnaire (PHQ-9) was used to assess the severity of depression, scores ranged from 0 to 27 (14). Depression severity was defined as: no depression (0-4), mild depression (5-9), moderate depression (10-14) and severe depression (15-27). A total score $\geq 8$ points on PHQ-9 was the cut-off for the presence of depressive symptoms (15). The Urdu version is a reliable and valid tool for the screening and assessment of depressed patients (16). For measuring anxiety, we used the 7-item Generalized Anxiety Disorder (GAD-7) scale with a total score ranging from 0 to 21; severity of anxiety is classed as: normal (0-4), mild (5-9), moderate (10-14) and severe $(15-21)$. Scores greater than 7 points on GAD-7 indicated anxiety symptoms (17). The Insomnia Severity Index (ISI-7) is a well-validated screening instrument for use among patients with sleep problems (18). Total score ranges from 0 to 28 . It provides the scoring for normal ( $0-$ 7), subthreshold (8-14), moderate (15-21) and severe (2228) insomnia. The cut-off score for detecting symptoms of insomnia was 15. Reliability analysis showed that the internal consistency coefficients (Cronbach's $\alpha$ ) for the PHQ-9, GAD-7 and ISI were 0.90, 0.94 and 0.94 respectively in the present study.

To evaluate the psychosocial consequences of hospitalization, the participants were asked some openended questions based on previous research $(2,5)$. These were:

- How did you feel when you realized you were infected or suspected of being infected with coronavirus and had to be isolated/quarantined in hospital?

- How have you been feeling since admission to the hospital?

- What are your major concerns during hospital stay?

- What measures do you think would help you during this time?

The interviews took 45-60 minutes with a followup interview needed in some cases. All interviews were recorded and responses to the open-ended questions were transcribed verbatim with the patient's permission. Psychological support using psychological first aid principles was provided via telepsychiatric services. Faceto-face interviews were carried out if acute psychiatric symptoms emerged or if requested by treating the physicians. 
Data analysis was performed using SPSS, version 20.0. Descriptive analysis was done to assess the demographic characteristics of the patients. Data for each level for symptoms of depression, anxiety, insomnia, and stress and adjustment disorder are presented as numbers and percentages. The chi-squared test was used to compare the severity categories of scales between groups (sex; duration of quarantine of 1 week or more). Independent samples t-test was used to test for differences in continuous variables (mean scores of scales) between groups. The significance level was set at $\alpha=0.05$. Patients' responses to the open-ended questions were coded and interpreted by the content analysis method. Two researchers independently reviewed and compared the answers several times to ensure accuracy and recode them, by agreement.

\section{Results}

The psychological assessments were completed by 114 patients; 102 (89.5\%) were confirmed and 12 (10.6\%) were suspected COVID-19 cases; 61 (53.5\%) patients were male and $53(46.5 \%)$ were female; the mean age was 38.8 [standard deviation (SD) 15.3, range 18-67] years (Table 1). The mean duration of stay was 7.9 (SD 4.1) days.

Table 2 summarizes the concerns, stress-related symptoms and associated behaviours identified by patients following COVID-19-related hospitalization. The most common stress-related symptoms reported were irritability (97.4\%), anxiety (65.8\%), sleep problems (43.0\%) and fear of affecting family (39.5\%).

The prevalence of adjustment disorder and acute stress disorder, according to DSM-5 criteria, in hospitalized COVID-19 patients was $67.5 \%$ and $3.5 \%$ respectively. According to the PHQ-9, GAD and Insomnia Scale criteria, $19(16.7 \%)$ participants were depressed (PHQ-9 28); 21 (18.4\%) were anxious (GAD-7 $\geq 7$ ) and insomnia was reported in $34(29.8 \%)$ patients.

Among hospitalized COVID-19 patients, women had higher mean scores for depression [5.06 (SD 5.36) vs 4.13 (SD 4.05)], anxiety [4.26 (SD 5.25) vs 4.16 (SD 4.05)] and insomnia (8.23 (SD 6.69) vs 7.92 (SD 5.61)] but these were not statistically significant $(P>0.05)$. Similarly, duration of hospitalization of more than 1 week did not show any statistically significant difference in psychological measures except for insomnia [9.18 (SD 5.95) vs 6.95 (SD 6.12); $P \leq 05]$.

One of the male patients (6o years old) tried to commit suicide during hospitalization because of worries about his family and guilt over being unable to provide for them due to hospitalization. He was also unable to attend the funeral of his mother, who passed away during his period of isolation, which added to his distress.

Women reported experiencing more severe levels of anxiety [e.g. severe anxiety among females compared with males: $3(2.6 \%)$ vs $1(1.6 \%) ; P=0.018]$, but not for other variables (Table 3).

\begin{tabular}{|c|c|}
\hline Characteristic & Mean (SD) \\
\hline Days since admission to hospital & $7.85(4.1)$ \\
\hline \multirow[t]{2}{*}{ Age (years) } & $38.8(15.3)$ \\
\hline & No. (\%) \\
\hline \multicolumn{2}{|l|}{ COVID-19 test result } \\
\hline Positive & $102(89.5)$ \\
\hline Awaiting result & $12(10.6)$ \\
\hline \multicolumn{2}{|c|}{ Any other family member also having COVID-19 } \\
\hline Yes & $67(58.8)$ \\
\hline No & $47(41.2)$ \\
\hline \multicolumn{2}{|l|}{ Sex } \\
\hline Men & $61(53.5)$ \\
\hline Women & $53(46.5)$ \\
\hline \multicolumn{2}{|l|}{ Marital status } \\
\hline Unmarried & $27(23.7)$ \\
\hline Married & $85(74.6)$ \\
\hline Separated/divorced & $2(1.8)$ \\
\hline \multicolumn{2}{|l|}{ Occupation } \\
\hline Unemployed & $2(1.7)$ \\
\hline Housewife & $24(21.0)$ \\
\hline Student & $19(16.6)$ \\
\hline Unskilled worker & $24(21.0)$ \\
\hline Skilled worker & $46(40.3)$ \\
\hline \multicolumn{2}{|l|}{ Education } \\
\hline Illiterate & $6(5.3)$ \\
\hline Up to grade 5 & $19(16.7)$ \\
\hline Up to matriculation & $48(42.1)$ \\
\hline Graduate & $30(26.3)$ \\
\hline Professional degree & $11(9.6)$ \\
\hline \multicolumn{2}{|l|}{ Area } \\
\hline Urban & $107(93.9)$ \\
\hline Rural & $7^{(6.1)}$ \\
\hline \multicolumn{2}{|l|}{ Travel history } \\
\hline Yes & $13(11.4)$ \\
\hline No & $101(88.6)$ \\
\hline \multicolumn{2}{|c|}{ History of contact with COVID-19 patient } \\
\hline Yes & $65(57.0)$ \\
\hline No & $49(43.0)$ \\
\hline \multicolumn{2}{|c|}{ History of any previous medical illness } \\
\hline Yes & $6(5 \cdot 3)$ \\
\hline No & $108(94.7)$ \\
\hline \multicolumn{2}{|c|}{ History of any previous psychiatric illness } \\
\hline Yes & $6(5.3)$ \\
\hline No & $108(94.7)$ \\
\hline
\end{tabular}

$S D=$ standard deviation.

There were no statistically significant differences in severity of symptoms of depression, anxiety or insomnia among patients isolated for more than one week or having a family member who also had COVID-19 $(P>0.5)$. 


\begin{tabular}{|c|c|}
\hline Stress-related symptoms and behaviours & No. (\%) \\
\hline Irritability & $111(97.4)$ \\
\hline Anxiety & $75(65.8)$ \\
\hline Sleep problems & $49(43.0)$ \\
\hline Afraid due to fear of infecting family & $45(39.5)$ \\
\hline Frustration & $34(29.8)$ \\
\hline Feeling scared for no reason & $34(29.8)$ \\
\hline Anger & $22(19.3)$ \\
\hline $\begin{array}{l}\text { Investing majority of free time reading or watching } \\
\text { corona-related information }\end{array}$ & $13(11.4)$ \\
\hline Exhaustion & $13(11.4)$ \\
\hline Pessimism/ hopelessness & $11(9.6)$ \\
\hline $\begin{array}{l}\text { Felt rejected in family/neighborhood because of } \\
\text { illness }\end{array}$ & $10(8.8)$ \\
\hline Absence of emotional response & $10(8.8)$ \\
\hline Poor concentration/indecisiveness & $7(6.1)$ \\
\hline Nightmares & $5(4.4)$ \\
\hline Detachment from others & $5(4.4)$ \\
\hline Deteriorating work performance. & $3(2.6)$ \\
\hline Reduced awareness or being in a daze & $2(1.8)$ \\
\hline $\begin{array}{l}\text { Avoiding information about corona as much as } \\
\text { possible }\end{array}$ & $2(1.8)$ \\
\hline Depressed mood & $1(0.9)$ \\
\hline
\end{tabular}

Qualitative data from interviews with patients provides insight into the possible psychosocial impact of COVID-19-related quarantine and isolation in hospital and highlights the perceived threat, confusion and isolation imposed by this type of health-related crisis. Table 4 shows example quotes extracted from the qualitative data analysis in relation to psychological consequences and sources of anxiety and stress. Patients adopted various personal coping strategies to cope with their stress and anxiety while they were hospitalized with a potentially deadly disease. Prayers, reading the Holy Quran and communicating with the family were the most commonly reported strategies.

\section{Discussion}

Infectious diseases remain one of the huge menaces for the well-being of the human race, and threaten not only the physical health but also the psychological and social health of those infected. To our knowledge, this study is the first to investigate psychological problems in hospitalized patients with suspected and confirmed COVID-19 in Pakistan using detailed in-depth interviews to address the immediate mental health impact of isolation and quarantine in hospitals. This baseline information also helped in developing a holistic approach to patient care through provision of psychological first aid using telepsychiatry services.

We found a high prevalence of symptoms of psychological distress and disorder in confirmed or suspected COVID-19 hospitalized patients. Our findings complement the existing literature on the psychological impact of infectious diseases. In studies done following previous outbreaks of similar illnesses, such as the outbreak of severe acute respiratory syndrome (SARS$\mathrm{CoV}$ ) and Middle East Respiratory Syndrome (MERS), patients were found to have compromised psychological health immediately after being infected or shortly after discharge from hospital $(2,3,6)$. Poor sleep, as well as nightmares, weepiness, depressed mood and poor concentration were much more prevalent in SARS patients compared with healthy controls (2). Irritability stands out as having high prevalence in our study sample (97\%), consistent with previous research (2). In a 2018 report, $70 \%$ of MERS patients quarantined in hospital exhibited psychiatric symptoms and $40 \%$ received psychiatric diagnoses (3). Qualitative studies have also identified a wide range of psychological responses to quarantine such as confusion, fear, anger, and anxietyinduced insomnia (5,19). Our qualitative data also reported similar themes of the psychological impact of COVID-19 but also identified various factors which increased distress among patients during hospitalization and which need to be addressed to improve their wellbeing. Tsang et al. noted that hopelessness due to various reasons, including financial concerns, can be so extreme that it may increase the suicide risk in infected patients (20). The feeling of helplessness was the most prominent finding in the patient in our study who tried to commit suicide. The incident also highlighted the fact that infected patients who are quarantined and have lower household incomes might require additional levels of support during hospitalization as empirical evidence indicated that economic strain and lack of social support also contribute to severe depression and may contribute to self-harm or suicidality in some cases $(21,22)$.

Women in our sample had higher mean scores on all psychological measures although these were not statistically significant. Female sex is associated with increased vulnerability to psychological problems during infectious disease outbreaks; females have been found to be 3 times more likely to have psychiatric morbidity $(6,8)$.

We did not find any statistically significant association of depression and anxiety with duration of quarantine in the acute treatment phase. These results are different from some previous reports, which show that a longer duration of quarantine was associated with much poorer mental health, including anger, avoidance behaviours and post-traumatic stress symptoms $(23,24)$. Catalano et al. observed an increase in Hospital Anxiety and Depression Scale scores in patients which was proportionate to the duration of quarantine (7.25 at baseline to 8.83 in week 1 and 11.5 in week 2) (25). Due to limited resources, it was not feasible for us to repeat measures at intervals; this process may have helped determine any changes in psychological indices associated with duration of hospitalization. Quarantine of more than 10 days was noted in one study to be associated with higher PTSD symptoms (23). This calls for greater attention to longer 


\begin{tabular}{|c|c|c|c|c|}
\hline Category \& severity & $\begin{array}{c}\text { Total } \\
(n=114)\end{array}$ & $\begin{array}{c}\text { Men } \\
(n=61)\end{array}$ & $\begin{array}{l}\text { Women } \\
(n=53)\end{array}$ & P-value \\
\hline & No (\%) & No. (\%) & No. $(\%)$ & \\
\hline \multicolumn{5}{|c|}{ PHQ-9, depression symptoms } \\
\hline Normal & $64(56.1)$ & $34(55.7)$ & $30(56.6)$ & \multirow[t]{4}{*}{0.128} \\
\hline Mild & $38(33.3)$ & $24(39.8)$ & $14(26.4)$ & \\
\hline Moderate & $6(5,3)$ & $2(3.3)$ & $4(7.5)$ & \\
\hline Severe & $6(5.3)$ & $1(1.6)$ & $5(9.4)$ & \\
\hline \multicolumn{5}{|l|}{ GAD-7, anxiety symptoms } \\
\hline Normal & $71(62.3)$ & $33(54.1)$ & $38(71.7)$ & \multirow[t]{4}{*}{$0.018^{*}$} \\
\hline Mild & $28(24.6)$ & $22(36.1)$ & $6(11.3)$ & \\
\hline Moderate & $11(9.6)$ & $5(8.2)$ & $6(11.3)$ & \\
\hline Severe & $4(3.5)$ & $1(1.6)$ & $3(2.6)$ & \\
\hline \multicolumn{5}{|l|}{ ISI, insomnia symptoms } \\
\hline Absent & $64(56.1)$ & $35(57.4)$ & $29(54.7)$ & \multirow[t]{4}{*}{0.913} \\
\hline Subthreshold & $32(28.1)$ & $17(27.9)$ & $15(28.3)$ & \\
\hline Moderate & $15(13.2)$ & $8(13.1)$ & $7(13.2)$ & \\
\hline Severe & $3(2.6)$ & $1(1.6)$ & $2(3.8)$ & \\
\hline \multicolumn{5}{|c|}{ Criteria for adjustment disorder met } \\
\hline Yes & $77(67.5)$ & $42(68.9)$ & $35(66.0)$ & \multirow[t]{2}{*}{0.842} \\
\hline No & $37(32.5)$ & $19(31.1)$ & $18(34.0)$ & \\
\hline \multicolumn{5}{|c|}{ Criteria for acute stress disorder met } \\
\hline Yes & $4(3.5)$ & $1(1.6)$ & $3(5.8)$ & \multirow[t]{2}{*}{0.332} \\
\hline No & $109(96.5)$ & $60(98.4)$ & $49(94.2)$ & \\
\hline
\end{tabular}

PHQ-9 = 9-item Patient Health Questionnaire.

GAD-7 = 7-item Generalized Anxiety Disorder.

ISI $=7$-item Insomnia Severity Index.

${ }^{*}$ P-value $<0.05$.

follow-up of these patients to determine a range of mental health difficulties, which may continue to affect them long after the acute infection is under control. Our study also noted that hospitalized patients were affected simultaneously by a multitude of psychological problems and not merely struggling with isolated difficulties.

Two of the main themes behind the negative psychological effects in hospitalized patients were uncertainty and inadequate communication by health care providers. This is not surprising as studies have noted that regardless of hospital ward or intensive care unit settings, health care professionals spent less time with isolated than non-isolated patients (26). The requirement to wear personal protective equipment in hot weather and the need to see multiple patients may act as a barrier for health care workers to spend adequate time with patients, leading to a reduction in the duration of contact. It is unclear whether this shorter time spent with the patients is associated with adverse clinical outcomes; this needs further study. Davies and Rees found that keeping patients informed regarding their care is linked to patient satisfaction and should be a priority given the current situation of uncertainty and fear among hospitalized COVID-19 patients (27).
Our findings have significant clinical and practical implications. Given the nature of the negative psychological impact of COVID-19-related admissions in hospital, we established a patient-centred consultation programme and offered mental health services to all confirmed or suspected COVID-19 hospital patients, regardless of whether they were diagnosed with psychiatric disorders. Current research focuses on early detection of psychiatric symptoms in hospitalized patients. In the current study hospital, the research team sought to create a balance between strict isolation measures and face-to-face psychiatric assessment and intervention by providing telepsychiatry services and regular liaison with treating physicians and the hospital administration. Interventions also included fostering close contact with family members through regular phone contact and real-time video conferencing. Finally, all patients were encouraged to seek counselling at any time while hospitalized. This was much appreciated as it provided a sense of safety and security at a time of great psychological distress. Medical teams looking after COVID-19 patients were provided online psychological first aid training aimed at giving them the skills to alleviate symptoms of distress in patients as well as themselves. Many patients needed help with social 


$\begin{array}{lll}\text { Class \& subclass Code Quote: (patient ID no.-sex-age)) } & \text { C }\end{array}$

\section{Psychological consequences}

Fear of death and infection of other

Depression/ anxiety

Sleep problems

Feelings of anger family members
- Severe preoccupation about death.

- Severe preoccupation about infection/death of other family members.

- Frequent crying and low mood, worries

- Feeling lonely, anxious and unhappy

- Experiencing frequent insomnia from the severity of anxiety.

- Lack of peace, excessive noise

- Feeling anger about people being non-compliance with quarantine advice leading to increasing risk of spreading infection
"When we first tested positive, I thought we were all going to die because of what I had seen on the media. I was terrified." (P76-F-24) "We felt mortified when a patient in the ward passed away in front of us. I remember it all so vividly." (P8-M-20)

"A boy admitted with me mentioned that USA reported a thousand deaths in a day. I felt like my heart sank. I have a son admitted in PKLI's ICU. I fear what will happen to him."(P1-F-53)

"I have 3 daughters and a wife back at home in another city. I am the only bread winner and have been away from them for 1.5 months now. I am so stressed about how they are managing expenses back at home. Do they have enough to feed themselves? I need to go home." (P73-M-60) He wept while narrating his dilemma. A week later, he tried to commit suicide.

"I worry that I will die here alone. I feel so lonely and alone." (P17-F-68) 68-year-old female patient started crying during the interview while talking about missing her grandchildren.

"It is very hard to sleep here as I feel anxious. I try to catch up on my sleep in the evening but then spend sleepless nights." (P30-F-36) "It's been 6 days since my admission and my sleep quality is very poor. There is so much noise and disturbance at night that I cannot fall asleep. The day is no different." (P69-M-36)

One mother expressed anger about risk being posed to her kids at home.

"My mother in law also tested positive but she is still at home and not isolating. There are small kids at my place, I am so worried. Called 1166 multiple times to bring her to the hospital too but no one is paying any heed to my requests." (P63-F-36)

\section{Source of anxiety and distress}

Inadequate communication

- Lack of communication from hospital administration

- Poor information from treating staff especially related to test results

\section{Poor ward facilities}

Distress and concern about family members
- Poor hygiene

- Inadequate ventilation of rooms

- Poor internet facilities

- Poor food quality

- Feeling forgotten and rejected by family

- Preoccupation with health of family members at home and in hospital

- Not disclosing hospitalization due to possible family distress
"I have been using all my efforts to know how my tests have turned out, are they negative for corona now or not? I was not informed even after asking." (P10-M-25)

"First of all, they don't take our samples despite being here for several days and when they do, we are not informed of the reports. We inquire about them repeatedly but there is no reply from the administration and doctors. This behaviour is not helping our anxiety." (P54-M-18)

"There are heaps of garbage and filth here. The bed sheets are stained and the whole situation is deplorable. My youngest son is with me. How do they expect us to stay in such conditions?" (P39-F-38) "I felt trapped in the room, there was no ventilation which makes me feel suffocated. I knocked at the door but they had bolted it from the outside." (P19-F-30)

"The ward I am staying in does not have WIFI. I wish there was a better signal so I could communicate with my family, right now the signal breaks and the calls end abruptly. I am not allowed to go out of the ward for better reception." (P5-F-25)

"I wish the hospital served us hygienic and fresh food as I read that the viral infection can be fought off with a good diet." (P9-M-56)

"I am missing my 3 children who are at my mother's home. I talk to them over video calls but they appear indifferent; that hurts me. My wish is to return home as soon as possible so I'll be able to cook for them myself." (P34-F-38).

"I have 2 kids at home, they call me every day and cry because I am not with them. I cannot sleep at night worrying about my kids, desperately waiting for the results." (P44-F-32).

"I am concerned about how my husband's result comes out; he was tested after me and is also in a quarantine facility. He is diabetic and needs blood sugar monitoring." (P16-F-55)

One patient reported not telling his mother and children living in another city about his illness and hospitalization because he did not want them to worry. He stated: "Media reports that that those who are isolated end up in the grave and there is no one to say their funeral prayers. I don't want them to suffer by knowing about me being isolated." (P-109-M-42) 


\begin{tabular}{|c|c|c|}
\hline Class \& subclass & Code & Quote: (patient ID no.-sex-age)) \\
\hline Financial concerns & $\begin{array}{l}\text { - Worries about hospital expenses } \\
\text { - Disruption in work life }\end{array}$ & $\begin{array}{l}\text { "We belong to a middle-class family, my } 5 \text {-year-old son asked me } \\
\text { yesterday 'Is the food served here free? Will they charge us for } \\
\text { medication?' I had tears in my eyes. I told him Allah will help us get } \\
\text { out and back to our own home." (P31-F-32) }\end{array}$ \\
\hline $\begin{array}{l}\text { Improper behaviour of fellow } \\
\text { patients }\end{array}$ & $\begin{array}{l}\text { - Fellow patients making videos } \\
\text { of other patients/staff } \\
\text { - Lack of respect to dead body } \\
\text { - Breach of confidentiality }\end{array}$ & $\begin{array}{l}\text { One female patient developed stress-related symptoms after } \\
\text { witnessing the abnormal behaviours of another COVID-19 patient } \\
\text { who made a video of the body of a patient who died in their unit and } \\
\text { later posted it on social media. "I felt disgusted by his behaviour." } \\
\text { (P5-F-25) }\end{array}$ \\
\hline Social stigma and rejection & $\begin{array}{l}\text { - Humiliating behaviour/ attitude } \\
\text { of others } \\
\text { - Lack of social relations during } \\
\text { the quarantine period }\end{array}$ & $\begin{array}{l}\text { "They are treating us like we have AIDS." (P74-M-33) } \\
\text { "We are being kept isolated against our will as prisoners." } \\
\text { (P109-M-42) }\end{array}$ \\
\hline
\end{tabular}

PKLI = Pakistan Kidney and Liver Institute.

ICU = intensive care unit.

issues and financial assistance and were linked with appropriate services.

This study has some potential limitations. It was done in a single centre with purposive convenience sampling and a small study population, thus limiting the generalizability of the findings. Interviews were conducted by phone and there was lack of face-to-face communication. The strengths of the study included detailed in-depth interviews using the mixed methods approach, the use of validated assessment tools and patient-centred service provision.

\section{Conclusion}

The present study provides insight into the potential immediate psychological sequelae among COVID-19 patients in the resource-constrained setting of a low- or middle-income country. Our results show alarmingly high levels of stress-related symptoms, insomnia, depression and anxiety in COVID-19 confirmed or suspected hospitalized patients. An important practical implication of these findings is that these psychiatric issues can lead to noncompliance with infection control measures and reduced quality of life. Our results suggest the need to incorporate psychological services early in the acute phase of the illness. Adequate communication with patients during hospitalization, provision of basic needs, focus on spirituality and fostering of close social ties within the prescribed safety parameters are some of the critical component in reducing the short- and long-term negative consequences in COVID-19 patients. The long term psychological needs of these vulnerable patients warrant monitoring as we continue to grapple with the evolving COVID-19 outbreak.

\section{Funding: None.}

Competing interests: None declared.

\section{Impact psychiatrique sur les patients atteints de COVID-19 isolés dans un hôpital de soins tertiaires au Pakistan}

\section{Résumé}

Contexte : Des effets psychologiques négatifs ont été associés aux mesures de confinement liées à la COVID-19, mais peu d'informations sont disponibles sur les symptômes psychiatriques et la détresse.

Objectifs : La présente étude visait à explorer et à comprendre les symptômes psychiatriques et la détresse chez les cas suspects ou confirmés de COVID-19 isolés et mis en quarantaine à l'hôpital.

Méthodes : Une étude à méthodologie mixte a été menée dans les services COVID-19 de l'hôpital Mayo à Lahore (Pakistan) ; 114 patients adultes sur 160 ont été évalués par téléphone à l'aide d'échelles validées (liste de contrôle des réactions au stress et des troubles d'ajustement, questionnaire à neuf items sur la santé des patients, échelle à sept items sur les troubles anxieux généralisés et indice de gravité de l'insomnie). Ces patients ont également été évalués à l'aide de quelques questions ouvertes sur les attentes et les domaines escomptés pendant l'hospitalisation, y compris les expériences d'isolement.

Résultats : La prévalence des troubles de l'adaptation, des troubles aigus du stress, de l'anxiété, des symptômes dépressifs et de l'insomnie était respectivement de 67,5 \%, 3,5 \%, 16,7 \%, 18,4 \% et 29,8 \%. Un patient de sexe masculin a tenté de se suicider pendant la période de l'étude. La peur, la colère, la mauvaise humeur, l'anxiété et les troubles du sommeil étaient les conséquences psychologiques les plus notables dans les réponses qualitatives. Le manque de communication, le mauvais état des salles, les préoccupations concernant la santé des membres de la famille et les problèmes financiers étaient les facteurs de détresse les plus couramment identifiés. 
Conclusion : Nos résultats montrent des niveaux alarmants de symptômes liés au stress - insomnie, dépression et anxiété - chez les patients hospitalisés avec suspicion ou confirmation de COVID-19. Il est nécessaire d'intégrer des services psychologiques dans la phase aiguë de la maladie afin de reconnaître et de prendre en charge rapidement les problèmes psychiatriques.

$$
\begin{aligned}
& \text { التأثيرات النفسية على مرضى كوفيد-19 المعزولين في مستشفى للرعاية الثالثية في باكستان } \\
& \text { نازيش عمر ان، إروم عامر، هادية أفضل، علي هاشمي، بلقيس شابير، أفتاب عاصف }
\end{aligned}
$$

الخلفية: ارتبطت التأثيرات النفسية السلبية بتدابير احتو اء الأمراض المتعلقة بمرض كوفيد-19، ولكن لايُعرف إلا القليل عن الأعراض النفسية والشعور بالضائقة.

الأهداف: هدفت هذه الدراسة إلى استكشاف وفهم الأعر اض النفسية والشعور بالضائقة لدى المرضى المؤكدة إصابتهم بمرض كوفيد-19 أو

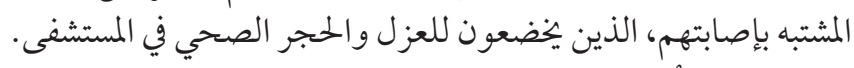

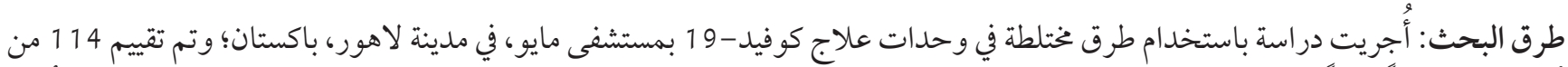

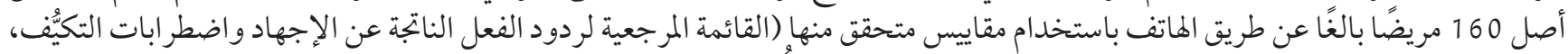

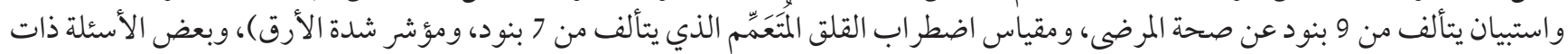

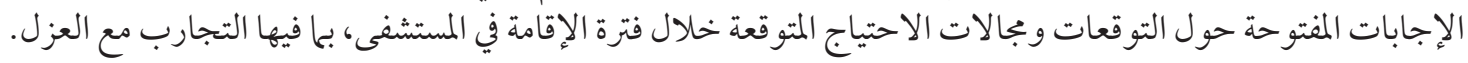

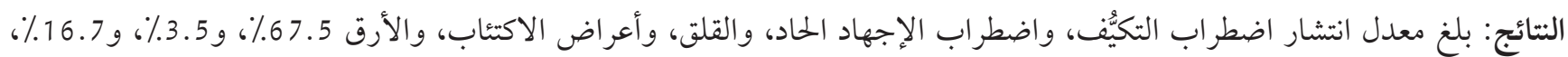

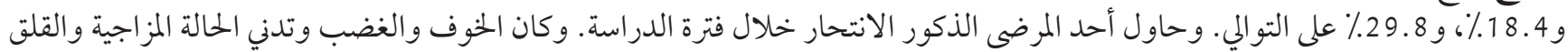

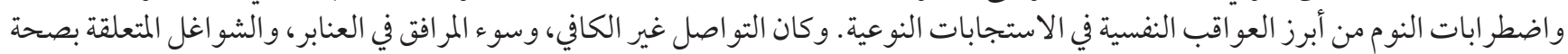

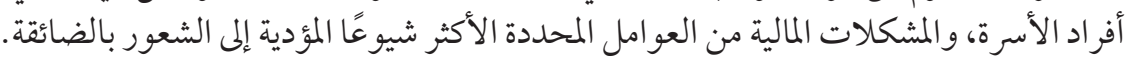

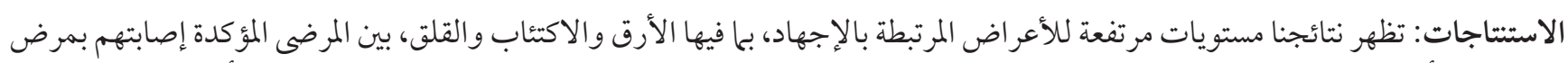

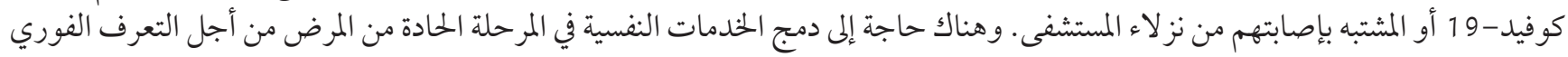
على المشكالات النفسية وعلاجها.

\section{References}

1. Li W, Yang Y, Liu ZH, Zhao YJ, Zhang Q, Zhang L, et al. Progression of mental health services during the COVID-19 outbreak in China. Int J Biol Sci. 2020;16(10):1732. doi:10.7150/ijbs.45120

2. Chua SE, Cheung V, McAlonan GM, Cheung C, Wong JW, Cheung EP, et al. Stress and psychological impact on SARS patients during the outbreak. Can J Psychiatry. 2004 Jun;49(6):385-90. doi:10.1177/070674370404900607

3. Kim HC, Yoo SY, Lee BH, Lee SH, Shin HS. Psychiatric findings in suspected and confirmed middle east respiratory syndrome patients quarantined in hospital: a retrospective chart analysis. Psychiatry Investig. 2018 Apr;15(4):355-60. doi:10.30773/ pi.2017.10.25.1

4. Lee DT, Wing YK, Leung HC, Sung JJ, Ng YK, Yiu GC, Chen RY, Chiu HF. Factors associated with psychosis among patients with severe acute respiratory syndrome: a case-control study. Clin Infect Dis. 2004 Oct 15;39(8):1247-9. doi:10.1086/424016

5. Aliakbari Dehkordi M, Eisazadeh F, Aghajanbigloo S. Psychological consequences of patients with coronavirus (COVID-19): a qualitative study. Iran J Health Psychol. 2020;2(2):9-20.

6. Cheng SK, Wong CW, Tsang J, Wong KC. Psychological distress and negative appraisals in survivors of severe acute respiratory syndrome (SARS). Psychol Med. 2004 Oct;34(7):1187-95. doi:10.1017/s0033291704002272

7. Wu KK, Chan SK, Ma TM. Posttraumatic stress after SARS. Emerg Infect Dis. 2005;11:1297-1300. doi:10.3201/eid1108.041083

8. Lee AM, Wong JG, McAlonan GM, Cheung V, Cheung C, Sham PC, et al. Stress and psychological distress among SARS survivors 1 year after the outbreak. Can J Psychiatry. 2007 Apr;52(4):233-40. doi:10.1177/070674370705200405

9. Brooks SK, Webster RK, Smith LE, Woodland L, Wessely S, Greenberg N, et al. The psychological impact of quarantine and how to reduce it: rapid review of the evidence. Lancet. 2020 Mar 14;395(10227):912-20. doi:10.1016/So140-6736(20)30460-8

10. COVID-19 situation. Islamabad: Ministry of National Health Services Regulations \& Coordination; 2020 (http://covid.gov.pk/, accessed 25 April, 2020)

11. Javed A, Khan MN, Nasar A, Rasheed A. Mental healthcare in Pakistan. Taiwan J Psychiatry. 2020;34:6-14.

12. Najam S, Chachar AS, Mian A. The mhgap; will it bridge the mental health treatment gap in Pakistan? Pak J Neurolog Sci. 2019;14(2):28-33. 
13. Bai Y, Lin CC, Lin CY, Chen JY, Chue CM, Chou P. Survey of stress reactions among health care workers involved with the SARS outbreak. Psychiatr Serv. 2004 Sep;55(9):1055-7. doi:10.1176/appi.ps.55.9.1055

14. Zhang YL, Liang W, Chen ZM, Zhang HM, Zhang JH, Weng XQ, et al. Validity and reliability of Patient Health Questionnaire-9 and Patient Health Questionnaire-2 to screen for depression among college students in China. Asia Pac Psychiatry. 2013 Dec;5(4):268-75. doi:10.1111/appy.12103

15. Manea L, Gilbody S, McMillan D. Optimal cut-off score for diagnosing depression with the Patient Health Questionnaire (PHQ9): a meta-analysis. Can.Med.Assoc. J.2012;184(3). doi:10.1503/cmaj.110829

16. Ahmad S, Hussain S, Akhtar F, Shah FS. Urdu translation and validation of PHQ-9, a reliable identification, severity and treatment outcome tool for depression. J Pak Med Assoc. 2018 Aug;68(8):1166-70. PMID: 30108380

17. Spitzer R.L, Kroenke K, Williams J.B, Lowe B. A brief measure for assessing generalized anxiety disorder: the GAD-7. Arch Intern Med. 2006 May 22;166(10):1092-7. doi:10.1001/archinte.166.10.1092

18. Yu DS. Insomnia Severity Index: psychometric properties with Chinese community-dwelling older people. J. Adv. Nurs. 2010;66(10):2350-9. doi:10.1111/j.1365-2648.2010.05394.x

19. Abad C, Fearday A, Safdar N. Adverse effects of isolation in hospitalised patients: a systematic review. J Hosp Infect. 2010 Oct;76(2):97-102. doi:10.1016/j.jhin.2010.04.027

20. Tsang HW, Scudds RJ, Chan EY. Psychosocial impact of SARS. Emerg Infect Dis. 2004 Jul;10(7):1326-7. doi:10.3201/ eid1007.040090

21. Ali TM, Gul S. Community mental health services in Pakistan: review study from Muslim World 2000-2015. Psychol Community Health. 7;(1):57-71.

22. Mirza I, Jenkins R. Risk factors, prevalence, and treatment of anxiety and depressive disorders in Pakistan: systematic review. BMJ. 2004 Apr 3;328(7443):794. doi:10.1136/bmj.328.7443.794

23. Hawryluck L, Gold WL, Robinson S, Pogorski S, Galea S, Styra R. SARS control and psychological effects of quarantine, Toronto, Canada. Emerg Infect Dis. 2004 Jul;10(7):1206-12. doi:10.3201/eid1007.030703

24. Reynolds DL, Garay JR, Deamond SL, Moran MK, Gold W, Styra R. Understanding, compliance and psychological impact of the SARS quarantine experience. Epidemiol Infect. 2008 Jul;136(7):997-1007. doi:10.1017/S0950268807009156

25. Catalano G, Houston SH, Catalano MC, Butera AS, Jennings SM, Hakala SM, et al. Anxiety and depression in hospitalized patients in resistant organism isolation. South Med J. 2003 Feb;96(2):141-5. doi:10.1097/01.SMJ.0000050683.36014.2E

26. Evans HL, Shaffer MM, Hughes MG, Smith RL, Chong TW, Raymond DP, et al. Contact isolation in surgical patients: a barrier to care? Surgery. 2003;134(2):180-8. doi:10.1067/msy.2003.222

27. Davies H, Rees J. Psychological effects of isolation nursing (1): mood disturbance. Nurs. Stand. 2000;14(28): 35-8. doi:10.7748/ ns2000.03.14.28.35.c2799 